\title{
A patient's diary: episode 15 - the new neighbour
}

On Sunday afternoon I was washing the car when our new neighbour, the bearded man from No 27, crossed the road to have a word with me. He and his wife actually moved in about a month ago but Hilda and I for one reason or another had not so far made their acquaintance. It's not that we're snobbish or anything - it's just that they didn't seem quite the Chestnut Avenue type. Anyway when I saw him coming towards me I decided to put prejudice aside and greeted him with neighbourly cordiality. After a few exchanges about the weather and the garden, he said he'd been told that I was very knowledgeable about health matters and he wondered if I could recommend a good doctor in the area.

'Do you mean,' I said, 'that you have been here a month and you haven't registered with a doctor yet? That's very risky.' Then he explained that he was in fact registered with Patients First, the new style 'polyclinic' in the High Street. But although they have very smart new premises and are open all hours, he wasn't really satisfied with the service he was getting.

'Might I enquire' I said, 'in what respect you find your present medical advisers lacking?' Then he explained (in confidence) that he had suffered a good deal from bad nerves ever since he was trapped in a lift in 1993 and had to be cut free with welding torches. The experience had also resulted in recurrent headaches relieved only by very strong painkillers, which Patients First were, for some reason, reluctant to prescribe. $\mathrm{He}$ suspected it was to do with financial budgets and NHS constraints.

Furthermore, the last doctor he saw (whose name he couldn't remember) had refused to give him an adequate dose of his nerve tablets, despite the fact that a top Harley Street psychiatrist had said he would need them for the rest of his life. The trouble was, he confided, that none of the Patients First staff were prepared to devote enough time to studying his case in depth. They rushed you in, asked you all sorts of questions about smoking and exercise, gave you leaflets about cholesterol and sent you off to someone else for diets and breathing tests. You hardly ever saw the same person twice and some of them were not even proper doctors. So who did I recommend? It was on the tip of my tongue to suggest Dr Brenda Phillips, but then I thought - no. It's already quite difficult to get an appointment with her and the addition of another complex case to her list might prevent her from giving enough time to her existing patients.

'I think,' I said, 'that Dr Gerald Teacher is the man you are looking for, of Drs Grimes, Teacher, and Phillips, The Old Surgery, Acumen Road. Why not pop round there tomorrow with your medical card and have a word with their helpful reception staff?'

To my surprise, the bearded man said would I do him a big favour and introduce him personally? It seems that he is also subject to agoraphobia and was afraid that his nerves might let him down if he went on his own. 'Well, it just so happens,' I said, 'that I have to go to the surgery anyway tomorrow afternoon, nothing serious, just a bit of pancreatic trouble, so if you like, l'll knock on your door and pick you up about 4 p.m.' At this point, we introduced ourselves and I learned that his name was Jim Junkin. He has been in the engineering business all his life but is now unfortunately on 6 month sick notes because his indifferent health will not stand up to the strain. 'You see, Norman,' he said, 'I have what the nerve specialists call a personality disorder and there is no known cure.' I couldn't help feeling sorry for him. His personality irreparably damaged by a faulty elevator. I shall always use the stairs in future.

So on Monday afternoon we set off together for the surgery. When we arrived we found Elena, the practice manager, doing a stint at reception. Elena is from Venezuela but she speaks excellent English with an attractive little accent. However, when Elena was introduced to Jim she became rather hesitant and dubious. She looked at his medical card and said they didn't normally take patients wanting to change practice without discussing it with the doctors. Jim said he was feeling very ill and had completely run out of his tablets. It was an emergency, he said. Elena looked even more dubious and said she would have to speak to the doctor about it. She picked up the phone and had a muttered conversation with $\mathrm{Dr}$ Teacher during which she kept darting hostile glances at Jim which can't have done his personality any good at all. Finally she said that Dr Teacher would see him as an emergency but she couldn't make any promises about registration. I said I would go in with Jim so he wouldn't be nervous.

In the event Jim seemed to relax in $\mathrm{Dr}$ Teacher's presence and was able to explain all about the headaches and the nerves and being stuck in the lift, although he didn't mention the personality disorder. He was particularly anxious to obtain a prescription for some medication called Serenium which is the only thing that affords him any relief. Strangely enough, Dr Teacher seemed just as unwilling as his colleagues down the road at Patients First to prescribe it and would only offer a number of inferior substitutes that Jim scornfully dismissed as 'useless'.

Dr Teacher remained adamant even when Jim said he could feel serious withdrawal effects coming on and did Dr Teacher want to read in the paper about him being found dead in the morning? In the end Jim rather lost his temper, l'm sorry to say, and used some language quite unsuited to a doctor's surgery. Then he stalked out, saying he was going to find a decent doctor somewhere else. It was all most embarrassing and I didn't know where to put myself. Dr Teacher told me I should be more careful about the company I keep and that Jim Junkin was almost certainly addicted to serenium. I returned home alone to Chestnut Avenue and walked quickly past No 27 gazing steadfastly ahead.

We are grateful to John Salinsky for these extracts from Norman Gland's diary

DOI: 10.3399/bjgp08X279580 